\title{
Problem-Based Learning and Capstone Course Teaching Strategies for University Social Responsibility: The Case of a Packaging Design Course
}

\author{
Chinlon Lin and Hui Tu \\ Hungkuang University, Taichung, Taiwan \\ https:// orcid.org/0000-0002-9720-8910 \\ https://orcid.org/0000-0001-9211-271X
}

\begin{abstract}
Most design courses in Taiwanese universities still follow the traditional teaching methods that cannot address the complex and interdisciplinary problems of the real world. In response to this, this study tries to integrate problem-based learning and capstone course approaches with university social responsibility to packaging design courses. It expects the hybrid teaching model will allow third-year college students to gain problem-solving skills, practical experience, and awareness of social responsibility in the design process. Therefore, this paper aims at addressing the following purposes: (1) explore each teaching approach's features and the influence on design education; and (2) identify the implementation process for the new hybrid teaching method. This study uses qualitative research to obtain primary information, including authors' observation and reflection and semistructured interviews with 12 students and four clients. After three years of data collection and analysis, this study validates that the hybrid teaching method is suitable for design education and proposes a sevenstage implementation model applied to professional design courses. Adjustment according to the needs of different fields, providing a reference for teachers' future curriculum planning and practice is included.
\end{abstract}

Keywords: capstone course; packaging design; problem-based learning; teaching strategies; university social responsibility

\section{Introduction}

When planning the curriculum and teaching of packaging design courses in design departments in Taiwanese universities, most courses still follow the standard guideline and mindset of the 1990s. The teaching strategies are limited to only exploring and teaching the forms, principles, and packaging processes. Students are assigned hypothetical themes that cannot address the complex and interdisciplinary problems of the real world. Design perspectives are becoming more fluid and complex in an era of rapidly changing design forms and materials. 
It is essential to re-examine the course structure to meet current industry needs and provide students with appropriate and professional materials.

In response to this issue, the packaging design course (the course) at the Department of Cultural and Creative Industries of Hungkuang University first adopted problem-based learning (PBL) in 2017. It later integrated the capstone course into its teaching. The concept of university social responsibility (USR) was applied to the assignment to establish a connection with the community. Based on the core concept of "learning by doing", PBL uses practical problems as the core of the teaching process and encourages students to engage in group discussions to develop their active learning, critical thinking, and problemsolving skills. This teaching method is believed to be more effective than traditional lecture-based learning. Capstone course is a method that focuses on industry orientation and stresses the assessment of students' core competencies. Through peer and external assessors' feedbacks, students can apply their core competencies to solving problems in the industry. In addition to the two teaching methods, the course also integrates the concept of USR to assignment topics which enable students to connect and grow with the community.

This study uses qualitative Action Research as its research method. Primary information is collected through authors' observation and reflection and interview feedback from the students and clients. After three years of data collection, this study discovers that students have acquired the ability to solve problems and develop critical thinking using a hybrid teaching approach. During the process, students learn to transform researched materials into design ideas, conduct market and case studies analysis, engage in repeated rounds of critiques with the teachers, industry experts, and the clients, reflect on feedback, and finally present their design works as a team. Thus, this study will address the following purposes: (1) explore each teaching approach's features and the influence on design education; and (2) identify the implementation process for the new hybrid teaching method. With this, the study hopes to construct a new teaching framework for packaging design courses that can cultivate a new generation of design talents and reference teachers' future curriculum planning and practice.

\section{Literature Review}

\subsection{Problem-Based Learning}

Problem-based learning (PBL) is a learner-oriented curriculum design that motivates active, cooperative, and practical learning. The concept of PBL was first proposed by the educator John Dewey (1859-1952), who advocated "learning by doing" instead of learning by passively receiving. He believes "true learning is based on discovery guided by mentoring rather than the transmission of knowledge" (Boyer, 1998, p. 15). Through "learning by doing," knowledge is acquired through action (Bender, 2012). In 2017, the Department of Technological and Vocational Education under Taiwan's Ministry of Education proposed the 2017 Pilot Program for Teaching Innovation in Technical Colleges and Universities, including the PBL course as a focus of the program. Subsequently, the "2019 Technical and Vocational Education Development Report" also identified PBL as the primary focus for enhancing the teaching practice in 
technical and vocational education. Therefore, tertiary institutions (not limited to technical colleges) such as Hungkuang University now consider PBL a crucial part of courses (Ministry of Education, 2019).

PBL is a method in which teachers use practical problems as the core of the teaching process and encourage students to engage in group discussions to develop their active learning, critical thinking, and problem-solving skills. This teaching method regards active learning as the focus of instruction and believes that active learning is more effective than traditional lecture-based learning (Hawks, 2014). Duch et al. (2001) asserted that PBL uses complex and real-world problems to encourage students to explore and study the concepts behind problems, allowing students to develop case studies from real-world problems. Through small learning groups and peer discussion, PBL also enables a more active and interactive process of learning, allowing students to develop solutions to problems rather than absorb knowledge passively (Yang \& Chang, 2005; Leung, 2008).

Tu et al. (2016) also argued that when carrying out PBL teaching, students can be motivated to participate in the course content and pursue self-achievement actively to reinforce their interest in the course content, practical application and relevance. This will not only increase students' level of satisfaction with the course, but it will also increase their satisfaction with the teaching resources, such as teachers' guidance and classroom equipment, as well as students themselves. In recent years, research on the use of PBL in teaching has diversified. Fan (2019) suggested that course curriculum should be practice-oriented to produce students to meet the needs and expectations of the workplace and employers, satisfying requirements for industry development. Al-Busaidi et al. (2021) believe that PBL emphasises the meaningful use of language as a tool for communication and problem-solving.

The implementation steps and key points of PBL have been in place for many years, and there are various versions and approaches, but the core concepts and aims are the same (Al-Busaidi et al., 2021). According to Barrett \& Moore (2011) and Flipped Education and Action Learning Association (2018), PBL can be divided into the following seven stages: 1 . problem-solving; 2. case-based; 3 . selfdirected; 4. small group discussion; 5 . tutor-assisted; 6 . self-assessment; 7 . development of interpersonal skills. Along with the teacher's guidance, students can learn to think about problem-solving during the one-year university course and serve the community and its needs.

\subsection{PBL Integrated Capstone Course}

When discussing the value of university education in recent years, demonstrating learning outcomes has become a core indicator for judging the quality of education. This is a significant difference from the past when only academics were examined. Following this trend, the capstone course has been widely applied in various disciplines. In terms of teaching, the capstone course represents the final year of the university experience; some departments also implement capstone courses in the third year. The course length is one or two semesters. Capstone 
courses should include four functions: integrating university learning experience, closure of the learning experience, reflection on the learning experience, and transition from university learning experience to the workplace (Gardner \& Van der Veer, 1998). The implementation of capstone courses can provide teachers with feedback on teaching and course improvement. It also helps students integrate their previous learning to produce specific results (i.e., creative works), enhance their ability, build confidence, and prepare for the future (Lee et al., 2019).

Maleki (2009) defined capstone courses that incorporate project-based, problembased, and inquiry-based learning as courses that emphasise the need for learners to work in teams to apply knowledge and think critically to accomplish learning tasks. Capstone courses integrate students' previous learning and outputs. Therefore, considerable emphasis is placed on students' ability to solve real-world problems. These problems are often complex and open-ended, so capstone courses are frequently combined with PBL teaching methods. The features of capstone courses should include the ability to highlight the department's specialities, the planning of learning processes that encourage active learning, knowledge sharing and teamwork, the production of designs that solve real problems, and teacher involvement and guidance. These features will increase students' interaction with the industry and develop learning applications (Dutson et al., 1997; Lee et al., 2019). Aside from emphasising industry orientation, capstone courses stress the assessment of students' core competencies. Peer assessment among students allows them to evaluate each other's works and learn from one another (Wu \& Cheng, 2014). In addition, inviting external teachers or trained assessors to serve as assessment committee members (Heitmann, 1996; Oscarson, 1989) can enable students to understand their performance and skills and apply their core.

\subsection{Praxis of University Social Responsibility}

University Social Responsibility (USR) is a humanism-based concept driven by local demand and implemented through students' participation in solving problems. USR was first discussed in the book entitled Beyond the Ivory Tower: Social Responsibilities of the Modern University by Derek Bok in 1984. They argued that universities must uphold their fundamental values and functions and think deeply about their social responsibilities and escape from the ivory tower in their teaching and research. The Higher Education Institution (HEI) discusses the contributions of USR, arguing that USR is a social philosophy or principle that plays a crucial role in social change to sustain social, ecological, environmental, technological, and economic development. USR is an interactive dialogue between the university on the one hand and society and the community, on the other hand, providing services through the transformation of knowledge to promote sustainable human development and research (Matten \& Moon, 2004). Participating in the communities can shape a university's research agenda and enhance students' learning. In other words, USR integrates or establishes connections with the local community through teaching so that students and the community can learn from each other and grow together. In addition to traditional teaching and research, universities' role and mission of participating in and serving society are also essential responsibilities that enable students to 
have a sense of social mission and lead to the progressive development of society (Chiang \& Chuang, 2018; Wu, 2018).

In addition to the theoretical and thematic convergence in the implementation of USR, Yamazaki (2015) proposed using the concept of community design to connect people through activities participation. He believes that design is a "powerful tool" for addressing social issues and uniting communities. Therefore, it is necessary to identify community resources, clarify the structure of the design theme, think about how to combine various elements and sustain enthusiasm. In his book entitled The Age of Community Design, Yamazaki (2018) divided community design into four stages: (1) Interview: collecting related local information; (2) Workshop: designers creating designs through interacting with people in the community; (3) Teambuilding: building the respect, communication, and coordination among team members, and assigning the roles and jobs of each individual; and (4) Action: providing the team with various types of support during the implementation process. Yamazaki (2018) mentioned the importance of focusing on what the community has and what the community wants to create. In this sense, during the development of community design, designers should pay attention to the locality and originality and respect the diversity of local culture to create an ideal lifestyle, from the bottom up, based entirely on the wishes of community residents.

\subsection{Research Hypothesis}

Based on the literature review and the author's personal teaching experience, this study hypothesises that by integrating PBL, capstone course, and the concept of USR to the teaching method, students will acquire the capability to solve realworld problems. In addition, the result of students' design work will demonstrate the concept of social responsibility.

\section{Methodology}

\subsection{Teaching Methods}

The authors have taught the packaging design course of Hungkuang University since 2017. The course is carried out with a hybrid teaching method that combines PBL with the capstone course approach and the praxis of USR. The course starts with an introduction to let students familiarise themselves with the overall packaging design process while building their professional judgment, selecting materials, and processing methods. The course is divided into two-semester and is taught to the third-year design students in the Department of Cultural and Creative Industries. The course curriculum is broadly divided into three themes each semester, with the concept of USR gradually blended in. This allows students to understand the impact of design on the social environment and consumers through hands-on design practices and case studies analysis. Students are assigned actual design topics which require them to communicate with both the clients and users repeatedly.

The seven stages of PBL are implemented through a collaborative design process in small groups of 2-4 people: 1. problem-solving; 2 . case-based; 3 . self-directed; 
4. small group discussion; 5. tutor-assisted; 6. self-assessment; 7. development of interpersonal skills (Table 1).

Table 1. The seven stages of PBL

\begin{tabular}{|c|c|}
\hline Step 1. & \\
\hline \multicolumn{2}{|c|}{$\begin{array}{l}\text { Students explore various aspects of the theme, such as users of the objects, market } \\
\text { position, design goals, and shape and structure. }\end{array}$} \\
\hline Step 2. & Case-based \\
\hline \multicolumn{2}{|c|}{$\begin{array}{l}\text { Besides using the real case as the theme, students need to conduct case studies from } \\
\text { Taiwan and overseas. Later, students are guided to visit and interact with the target } \\
\text { object and site to clearly define the theme and integrate the design into the real } \\
\text { environment. }\end{array}$} \\
\hline Step 3. & Self-directed \\
\hline \multicolumn{2}{|c|}{$\begin{array}{l}\text { Students convert the information collected from the previous steps into design ideas } \\
\text { and use case studies to search for the most suitable design techniques and styles to } \\
\text { execute the ideas. }\end{array}$} \\
\hline Step 4. & Small group discussion \\
\hline \multicolumn{2}{|c|}{$\begin{array}{l}\text { With each member's role and job functions assigned according to the individual's } \\
\text { expertise, students are asked to work as a team to find solutions through interactive } \\
\text { discussions and gradually construct the design proposals. }\end{array}$} \\
\hline Step 5. & Tutor-assisted \\
\hline \multicolumn{2}{|c|}{$\begin{array}{l}\text { After rounds of group discussions, students' design proposals are presented in the } \\
\text { classroom. The teachers then provide professional guidance, rather than giving the } \\
\text { "best" or "right" answers, for students to reflect on. }\end{array}$} \\
\hline Step 6. & Self-assessment \\
\hline \multicolumn{2}{|c|}{$\begin{array}{l}\text { After receiving suggestions and comments, each student digests the feedback } \\
\text { individually, then voice his/or opinions in group discussions. The training in this stage } \\
\text { focuses on students' self-assessment to identify the direction and extent of design } \\
\text { modifications. }\end{array}$} \\
\hline Step 7. & Development of interpersonal skills \\
\hline \multicolumn{2}{|c|}{$\begin{array}{l}\text { This is the final stage of the design process. The format usually includes the design } \\
\text { literature, posters, and final product. During this stage, the course teachers, industry } \\
\text { experts, community representatives, clients, and other students are gathered to critique } \\
\text { the works. Students are to learn to express their ideas clearly and confidently. The } \\
\text { interactive process is also an essential basis for developing interpersonal relations and } \\
\text { prepares them for entering the real workplace. }\end{array}$} \\
\hline
\end{tabular}

The course also incorporates the capstone course approach to teaching. Students can reflect on their previous learning experiences and engage in the process of integration, closure, reflection, and transition, and thus fully integrated with professional skills and overall competence. Some of the themes that had been assigned to the course in recent years include the following types:

1. Community-based topics: Students use design processes, such as observation, interviews, and participation, to collate design issues, discover local characteristics and culture of the community, and then propose innovative and creative packaging design solutions. Producers of products from the community are invited to participate in the design assessment, and so the students can learn more about the local features. Examples include packaging design for dried pineapple from Nantou (2017), packaging design for peaches from Xinshe, Taichung (2017), black bean mooncake packaging/gift box design from Wuqi, Taichung (2017), sweet potato nougat 
design from Longjing, Taichung (2018), tangerine for Gonglaoping Community Development Organization in Fengyuan, Taichung (2019), and wine bottle packaging design for Hung Estate Winery in Waipu, Taichung (2020).

2. Schools and social welfare organisations related topics: Examples include packaging design for the shampoo set for the Department of Applied Cosmetology, Hungkuang University (2018), the Anoectochilus Tea for the Department of Food Science and Technology, Hungkuang University (2019), and the Cancer-nono Foundation gift set (2019).

3. Environmental sustainability and universal design-related social topics: this theme allows students to think about packaging design from environmental issues and sustainable development. Examples include value-added packaging design (2018), universal packaging design proposal (2018), and green packaging product design and implementation plan (2019). The aim is for students to understand how to balance business with environmental and social responsibilities as designers.

\subsection{Research Methodology}

The research method for this study is primarily action research. Action research is a part of educational research that studies a specific problem in a specific context, emphasising the immediate application of findings. Action research combines the action and research of the practitioners in an attempt to bridge the gap between theory and practice. It focuses on the resolution of practical problems and the development of the capacity for action. At the same time, it also emphasises the development of critical and reflective skills (Huang \& Tsai, 2003). Educators carry out "educational action research" based on the problems they encounter or occur in education (Tsai, 2007). Lewin (1946) developed the action research model, describing action research as a spiral of steps:
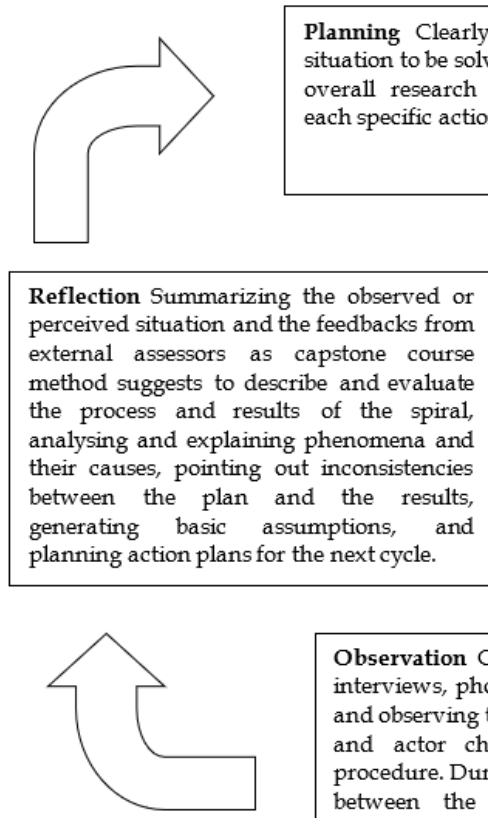

Observation Collecting data from in-depth interviews, photographs, and questionnaires, and observing the process, outcomes, context, and actor characteristics of each action procedure. During the process, the interaction between the teacher and students are recorded in written form.

Figure 1. Action Research Model

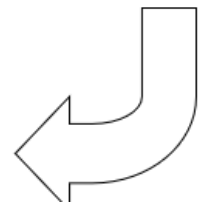

Implementing flexible action implementation plan. Actors' knowledge and decision making should be included after each procedure is implemented.

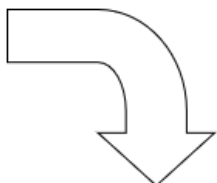

d


This study applies an action research model and is carried out through such processes as seeking the root of the problem, drawing up an action plan and process, implementing the action plan, observing and evaluating the effectiveness of the action strategy, evaluating the course, and incorporating reflection and feedback. The research materials include the teaching observations of the two teachers, student learning experiences and feedbacks, students' works (output), and interviews with clients. In reflection, the researchers provide feedbacks based on research materials and external assessors' opinions as the capstone course method suggests. Until all the stakeholders' information is collected and analysed, the research generates basic assumptions and plans another action plan for the new cycle.

\subsubsection{Data Collection}

Data collection is divided into preparatory, implementation, and reporting phases. In preparation, the two teachers consolidate previous teaching experiences and knowledge and record the observation on students' performance during the course. Four teams with grades ' $\mathrm{B}$ ' or above are chosen based on the purposive sampling method in the implementation phase. For three consecutive years, a total of 12 respondents, one student from each of the four chosen teams each year, was selected among 120 students who took the course between the academic years of 2017 and 2019 (Table 1). Gender selection is based on the female to male ratio of 3 to 1 in the class each year.

Table 1. Students who took the course between academic years 2017-2019

\begin{tabular}{|c|c|c|c|c|}
\hline No. & Code & Sex & Year & Sources Used \\
\hline 01 & $\mathrm{SC}$ & Female & 2017 & $\begin{array}{l}\text { Learning experience } \\
\text { reports, assignments }\end{array}$ \\
\hline 02 & ST & Female & 2017 & $\begin{array}{l}\text { Learning experience } \\
\text { reports, assignments }\end{array}$ \\
\hline 03 & SY1 & Female & 2017 & $\begin{array}{l}\text { Learning experience } \\
\text { reports }\end{array}$ \\
\hline 04 & SJ & Male & 2017 & $\begin{array}{l}\text { Learning experience } \\
\text { reports }\end{array}$ \\
\hline 05 & SL1 & Female & 2018 & $\begin{array}{l}\text { Learning experience } \\
\text { reports, assignments }\end{array}$ \\
\hline 06 & SS & Female & 2018 & $\begin{array}{l}\text { Learning experience } \\
\text { reports, assignments }\end{array}$ \\
\hline 07 & SW & Male & 2018 & $\begin{array}{l}\text { Learning experience } \\
\text { reports }\end{array}$ \\
\hline 08 & SL2 & Female & 2018 & $\begin{array}{l}\text { Learning experience } \\
\text { reports, assignments }\end{array}$ \\
\hline 09 & SL3 & Female & 2019 & $\begin{array}{l}\text { Learning experience } \\
\text { reports, assignments }\end{array}$ \\
\hline 10 & SL4 & Female & 2019 & $\begin{array}{l}\text { Learning experience } \\
\text { reports, assignments }\end{array}$ \\
\hline 11 & SY2 & Male & 2019 & $\begin{array}{l}\text { Learning experience } \\
\text { reports, assignments }\end{array}$ \\
\hline 12 & SL5 & Female & 2019 & $\begin{array}{l}\text { Learning experience } \\
\text { reports, assignments }\end{array}$ \\
\hline
\end{tabular}


Students were required to write a report on their learning experiences in the middle and end of each semester in the reporting phase. Students were also required to create and submit a portfolio of their work at the end of that semester. These materials are used to assess their learning outcomes and facilitate two-way dialogue between the teachers and students. Additionally, in-depth interviews were conducted on the students and clients after completing each assignment between the academic years of 2017-2019. The interviews were done in a semistructured style in which the interviewees were asked open-ended questions rather than a straightforward question-answer format. The interviewees were 12 students and four clients. The clients consisted of 2 males and two females who were the managers or owners of the organisations that commissioned the design projects (Table 2). The question outline was designed based on the concept of PBL, capstone teaching, and USR. Information elicited were first converted to a transcript and later analysed to look for any significant finding (Table 3).

Table 2. Clients between academic years 2017-2019

\begin{tabular}{lllll}
\hline No. & Code & Sex & Design Year & Sources Used \\
\hline $\mathbf{0 1}$ & DL1 & Male & 2018 & Personal interview \\
\hline $\mathbf{0 2}$ & DL2 & Female & 2018 & Personal interview \\
\hline $\mathbf{0 3}$ & DY & Female & 2019 & Personal interview \\
\hline $\mathbf{0 4}$ & DL3 & Male & 2019 & Personal interview \\
\hline
\end{tabular}

Table 3. Semi-structured interview questions

Q1. What are the differences between students' work and that of design firms'? Are the work conforms to industry standard and practices?

Q2. Have the students shown synergy between design and marketing strategies in their proposal?

Q3. Based on your experience during the final critique, do you think the works are presented and the theme of the assignments need to be revised or improved?

Q4. Have the students integrated the concept of USR into their works?

Q5. By integrating the concept of USR into the assignment theme, have students created something that brought changes to the community? 


\subsection{Research Process}

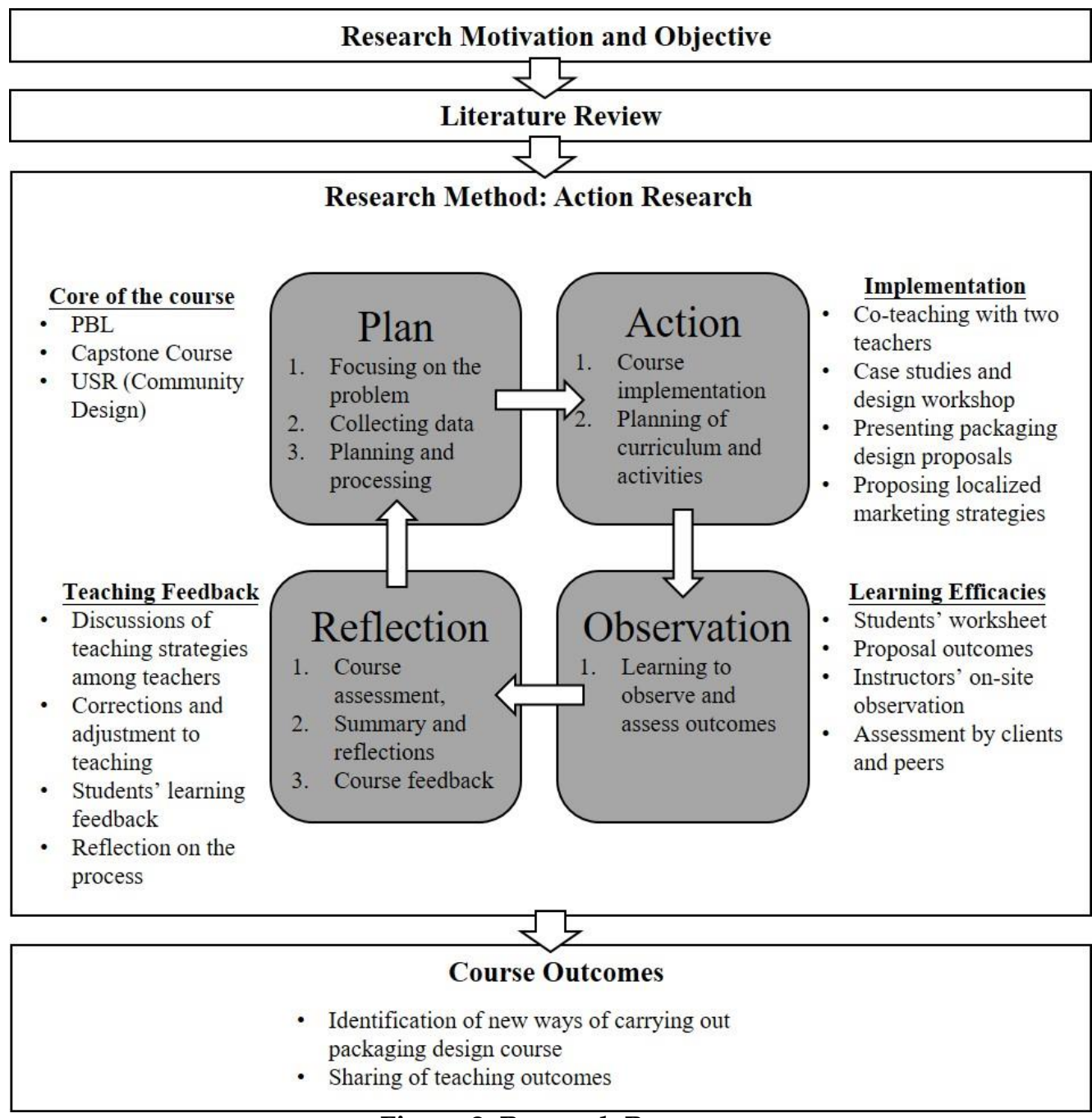

Figure 2. Research Process

\section{Discussion}

\subsection{Plan}

The Department of Cultural and Creative Industries of Hungkuang University underwent a department-wide curriculum restructuring in 2018 and positioned the course as an integrated professional design course that focuses on localisation in design. Therefore, in addition to the original PBL learning method, the course also embodies a capstone course approach to enable students to complete the learning experience of integration, closure, reflection, and transition and use their expertise to help to solve real-world problems in the community. Students receive concrete achievements from their learning outcomes through this process, which will later help them make a smoother transition between school and future working life.

To deepen students' learning, USR was incorporated into the course's design topics in 2019. In order to successfully carrying it out, the concepts of sustainable packaging design and universal design were also adopted for the first time, 
allowing students to design from the perspectives of environmental awareness and social issues. The goal of the course was to guide students to think and act from a professional designer's perspective and consequently maximise social responsibility through teamwork, innovation, and creativity. In addition, the course incorporated community design techniques that enable students to interact with residents and users and develop designs that integrate nature and local elements.

\subsection{Action}

Unlike conventional design teaching, two teachers are taught, both with professional backgrounds in design. The two teachers provide different viewpoints and case studies on the same topic, allowing students to think from multiple perspectives. In this section of the study, the implementation process of the course will be explicated in five stages: tasks and propositions, case-based, self-directed learning, group discussions, and tutor-assisted.

\subsubsection{Tasks and Propositions (Integration)}

In contrast to conventional packaging design training, the course hopes to utilise more local vocabulary and elements, allowing students to learn more about local features and the environment and processes for producing agricultural products based on their observations and interviews. The teachers provide case studies for every topic assigned and emphasise that design is not just about the final output but also analytical transformation and contextual construction. For example, for the assignment "packaging/gift box design for black bean mooncake from Wuqi, Taichung", SC-2017 described the process of developing propositions as follows: "I was asked to 'reawaken' the experiences and then 'reconstruct' them. At first, I was unable to adapt to this way of thinking. There was never a standard answer to the questions I raised; the teachers only gave two or three sentences as guidance and left the rest to me to think. Shouldn't the teacher give us clear instructions? After seeing case studies, we were asked to provide our views again. I really felt like there were too many things to think about and that it was too complicated. After few rounds of practice and note-taking, new ideas started to arise. Perhaps there are more possibilities for black beans from Wuqi. I slowly began to familiarise myself with the local features, and often times I would discuss them with my family. It's like they have become a new game in my life."

This student's progression from being unable to adapt to the eliciting teaching method to the method becoming a part of her life shows that the student could accumulate and internalise previous learning experiences. However, for students to connect, they require proper guidance and practice. Another example is the assignment "packaging design for sweet potato nougat from Longjing, Taichung" indicates that students can enhance their design ideas and creativity by acquiring others' life experience and professional knowledge. SL1- 2018 noted:

"If a good packaging design can convey this knowledge to more people, I believe Longjing's sweet potato nougat can differentiate itself from others and generate better sales."

Feedbacks from the client was positive as DL2-2018 commented that:

"We can see that students used many local elements in their proposals. This is something we rarely see from other companies in the industry. Maybe this was 
due to the advice given by the teachers or the way the course was carried out. We love this creative idea, so we decided to use this design for our product packaging."

In addition to visual effects, a good design must also be culturally rooted. Regarding the assignment "packaging design for tangerine for Gonglaoping Community Development Organization in Fengyuan, Taichung", SL4-2019 explained how they approach the theme:

"Our group came up with ideas from local eco-tourism. Based on the interviews and data collected, we decided to use local birds as the theme."

The client was delighted with the result and amazed by the student's creativity, as DL3-2019 pointed out:

"The students are full of creative ideas. They included a lot of community elements that we hadn't thought of ourselves in the proposal. The people in the organisation felt that they were very unique and everyone likes them. Unfortunately, it was not possible to mass-produce all of them."

The main reason the Organization preferred this group's work was its originality in marketing strategy. In contrast to the conventional representation of tangerine images, this group used birds that live in the same environment as the tangerines to illustrate its high-quality and pollution-free (Fig. 3). This approach enhances the reliability of the product and helps promote local features at the same time.

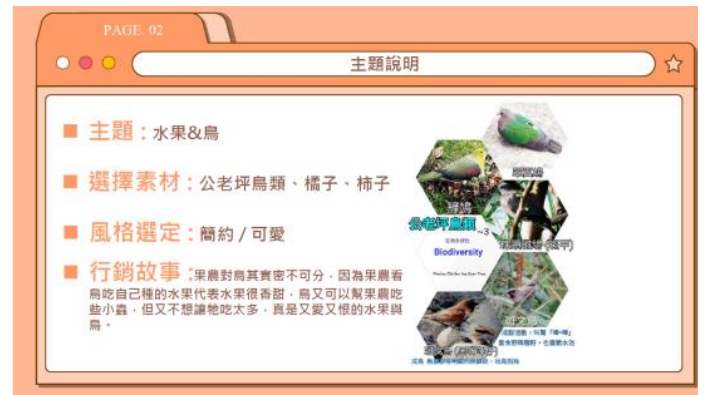

Figure 3-1. Conceptual design proposal

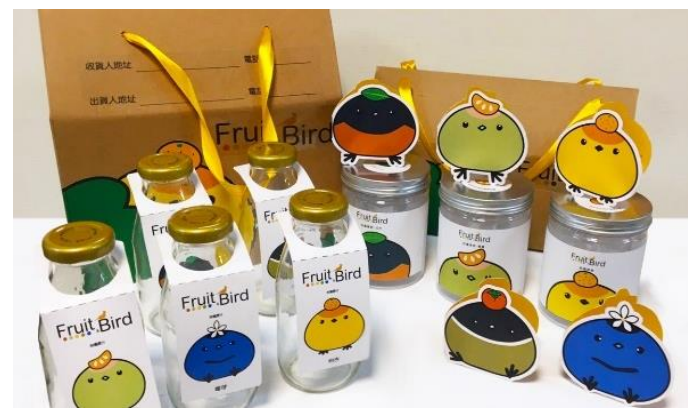

Figure 3-3. Integration of culture and local elements in packaging design
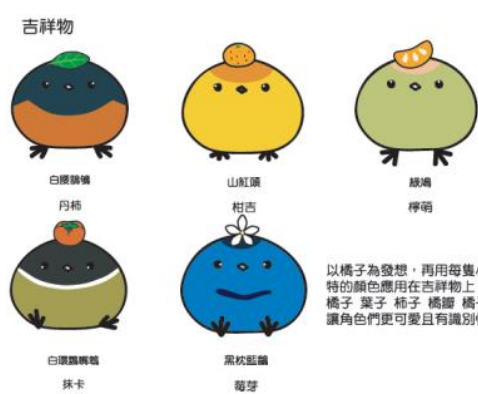

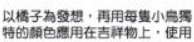

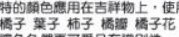

Figure 3-2. Characters setting

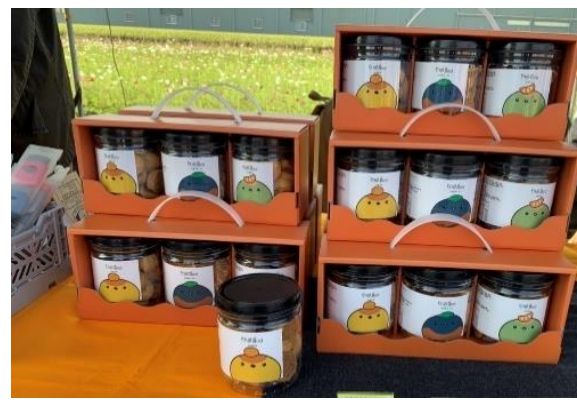

Figure 3-4. Final packaging design for mass production

Combining culture with local elements and successfully converting them into a conceptual design is key to assessing students' core competencies. Students have many creative ideas and observations that society and commercial designs have 
not yet ossified. Therefore, they can propose ideas from a unique perspective that distinguishes them from others.

\subsubsection{Case-Based (Integration)}

One of the main focuses of the course is case-based teaching. The course emphasises the significant relationship between design and users. A good packaging design should be based on the designers' understanding of the users and identify the leading target group. Students are asked to use market analysis, product analysis, in-depth interviews or questionnaires, and observation of consumer behaviour as data collection, aggregation, and judgment methods. These are to be converted into marketing strategies later. For example, in the assignment "shampoo set packaging design for the Department of Applied Cosmetology, Hungkuang University," students must first understand the basic information of the product, such as ingredients, features, primary customer, and sales channels, before they can conduct interviews with the clients or provide questionnaires to potential consumers. According to SL2-2018's experience report: "At first, we wanted to just mimic the design currently trending in the market. However, we discovered that apart from retail sale purposes, the product was going to be used as a school gift. Also, based on interviews, we know the client wanted the package to look luxurious and petite, emphasising its high-quality texture, and the bottle should be small and light enough for travel. On the contrary, the consumers wanted the price to be cheap and the capacity of the bottle to be big, hoping for the best value. Each party had a different view, and it was difficult to balance them."

Students' task with this case was not knowing which should be given priority or accommodating different views. As a result, they resolved these issues through communication, coordination, and design techniques. Team members discussed with both sides relentlessly and finally provided a solution that met both parties' cost/price, aestheticism, and practical needs (Fig. 4). This back-and-forth process is a common practice in the design industry, but not for students. As the client DL1-2018 noted:

"Because students lack experience in sales and marketing, they are less realistic in determining who the consumers are. From deciding the concept to the final design for mass production, we spent a lot of time going back and forth, revising and evaluating mock-ups. Although the final product looks very different from the students' original design, the main concept was still there. As a result, the product was very well-received, and everyone thought it was great. This gave us the confidence to continue collaborating with the course. We also hope by doing so allows students' works to be seen and gives them a real sense of achievement and recognition." 


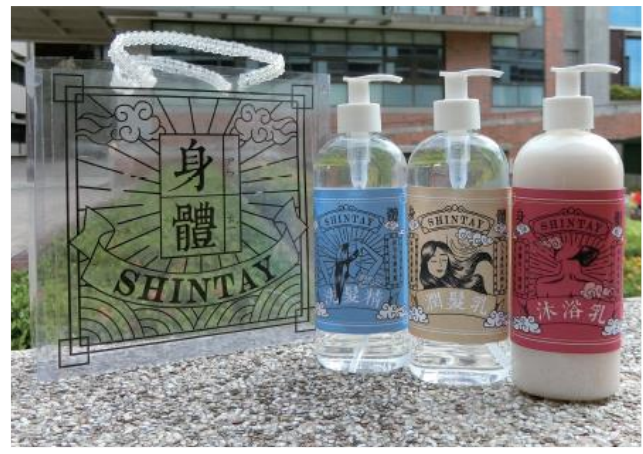

Figure 4-1. Creating design mock-ups

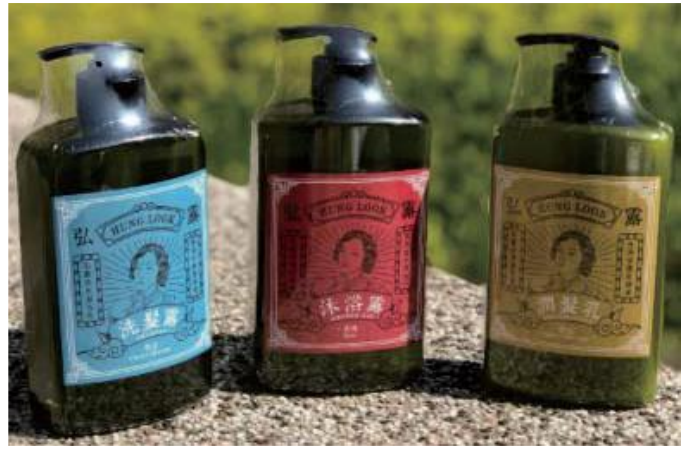

Figure 4-2. Final design for massproduction

\subsubsection{Self-Directed Learning (Closure)}

Although the course is carried out in small groups, each step along the way involves a process of self-directed learning. During the course, the teacher's guide students to identify problems from their past life experiences and encourage members from the group to provide suggestions and input for the problems, producing a continuous spiral learning experience between the student and his/her group. As two students expressed that:

SL2-2018: "At first, I simply used keywords to search for a case study for my design in the internet, but the results were not always suitable. With the teachers' guidance, I learn to contemplate on what I really want to achieve before making decisions."

SL5-2019: "After seeing the case studies provided by the teachers and the ones I researched, I usually comb my thoughts once again before presenting my ideas to the group for interactive discussion. By hearing other members' opinions, I gained a lot more."

In the beginning, students could not grasp the key points in self-directed learning and were not serious about the assignments. With the teachers' guidance, students have learned to integrate their strengths with learning experiences and optimise their self-directed learning.

\subsubsection{Group Discussion (Closure)}

Each stage of the course relies on the communication and collaboration between group members. These skills cannot be taught directly through teaching materials or theoretical explanations but rather from peers. Students need to keep an open mind and learn to listen to others' opinions and respect the decisions the group has made. They must also use effective methods and tools for team discussion and communication and propose the final design solutions. As students pointed out that:

SJ-2017: "The more members there are in a group, the harder it is to regulate. Many people are unwilling to accept the views of others or reluctant to express their views during the discussion but later demand to reverse the group's decision. This communication is ineffective."

SW-2018: "Teamwork is not an easy task for me. Particularly if the group members have conflicting views and we yet still have to select the best proposal." SS-2018: "I've learned how to accommodate each other over time; I can now patiently listen to other people's thoughts." 
SL3-2018: "I often hoped to use my idea as the group proposal. Because this was a group project, it was necessary to incorporate the views of other group members."

SY1-2017: "In the group discussion, I prefer everyone first putting forth his/her own design proposal, and after reviewing and identifying the pros and cons, the group decide on a proposal and move forward with it."

SL5-2019: "Nowadays, people like to use LINE group chats for discussion. I think group discussions should still be face-to-face in order to stay focused."

SC1-2017: "By working in a team, I was able to learn different ways of thinking and approaches to design from other students."

ST-2017: "Assigning roles and jobs allow everyone to take part in the project based on his or her strength; for example, those who are good at writing draft the plan and write the literature, and those who are better at craft build the models...etc."

Based on the above comments, it is clear that students have mixed feelings about working as a group. It is a standard practice in the industry, and students need to adapt and be prepared for their future employment. Students should accumulate experiences that include learning to listen, respecting decisions made, dividing work, collaborating, sharing, and reflecting on one another during their studies.

\subsubsection{Tutor-Assisted (Closure)}

Integrating USR into the course's curriculum requires more in-depth guidance for students and the provision of different design media. In addition to thinking about USR from multiple perspectives and the localisation of design, cultural, social, and environmental issues should also be incorporated so that students can learn practical skills and at the same time practice USR as they study. Two students described in the assignments "Value-added packaging design" and "Green packaging product design" as follows:

SS-2018: "This theme requires not only functionality but also added values, so there are more dimensions to consider. Packaging design combining environmental sustainability. I feel that there are many problems that need to be addressed, which make my design training more oriented."

SL3-2019: "The concept of green packaging allows us to rethink the role of designers. We should do our part for the environment and natural resources starting from design."

The clients gave positive feedback towards students' efforts to raise awareness of social responsibilities in their work.

DY-2019: "This time, the students designed products for us that fitted the theme very well. As a social welfare organisation, working with this course is a win-win situation."

DL3-2019: "The community needs young people in marketing and design like those from the Department of Cultural and Creative Industries. They can bring in a lot of fresh ideas. It would be good if the students could come more often to collaborate with us."

The scope of USR is vast. The teachers have explored elements of social responsibility, including environmental and sustainability development, local communities, and non-profit organisations, from different perspectives in the course, allowing students to integrate relevant knowledge acquired from the classroom with their design experience. For students in the technical and 
vocational education system such as Hungkuang University, the knowledge accumulated through direct hands-on experience is more valuable than gained through lectures.

\subsection{Observation}

Observation includes collecting data and observing each action procedure's process, outcomes, context, and actor characteristics. This part of the study is divided into two stages, self-assessment and development of interpersonal skills. The main focus of the two stages is to record the interaction between students and the teachers, external experts, the clients, and peers, and how the students apply the comments and suggestions back into their design proposition. Students' ability to communicate with others professionally and present works in industrystandard is critical for the assignment's success.

\subsubsection{Self-Assessment (Reflection)}

After group discussion and teachers' guidance, the most suitable solution is selected for the final proposal. From a practical design perspective, being aesthetically attractive is not the only thing that matters; a good design also needs to consider other factors such as having an appropriate theme, connections with the place, the users and the clients' needs, structure, and cost. The process involves individuals and the group's collective decisions to find the most suitable solution. As students describe below:

SC1-2017: "Model making is an important part of design process. I've learned to use sketch models to study and make necessary adjustment to my own proposition." SL3-2018: "If there's any adjustment needs to be made, we've learned to revisit the original design concept and try to propose another more suitable idea."

SS-2018: "The first time I created a design, I thought it was important to make it aesthetically beautiful. Until a critic told me during presentation that the packaging shouldn't be more expensive than the product, then I suddenly realised that our agenda was to design the packaging for the product, not to sell the packaging. Now, I've learned to always remember my goal and carefully calculate the cost and effect of the packaging and the products."

Using self-assessment to find the best solution for a design proposal is relatively challenging for students. On the one hand, they are required to be innovative and creative; on the other, they are asked to consider practicality. Over the years of teaching, it is evidenced that cost and practicality are the two factors that determine the success of a student's design. Hence, in this stage of the implementation process, demanding students to perform self-assessment is critical to their solution-finding and a crucial part of the design in the real-world environment.

\subsubsection{Development of Interpersonal Skills (Transition)}

When learning to communicate design ideas through a presentation, how students respond to differences in opinions is vital for accumulating and transitioning experiences. In addition to the two-course teachers, student's performance in the course is assessed by industry experts, representatives from the community, the clients (project commissioners), and occasionally their peers. Listening to opinions from their peers allows students to re-examine their ideas from different perspectives, which can later be applied back into the design. 
ST-2018: "I'm always nervous about presenting my proposal because I'm afraid that my design is not good enough, so I always rehearse over and over again to make sure I can clearly express my ideas."

SW-2018: "I am always nervous when the teachers say we are going to do peer assessment. It may not be easy for me to criticise the works of my friends without any personal feelings involved, but I try to do my best and be impartial."

Students must present their design proposals in this final stage; hence practical aspects of the design needs consideration. This interaction between the two counterparties, the presenter and the critics, allows students to learn to speak in public and be more familiar with actual industry practice. The inclusion of peer assessment also enables them to think about the feasibility and strengths and weaknesses of other proposals from a designer's perspective and not as a student. This is also the challenge they will be facing when working in the design industry in the future.

\subsection{Reflection}

This study uses a hybrid method to integrate three teaching strategies. Similar to Duch et al. (2001) argument, the course uses real-world problems as assignments for students to come up with solutions collectively in teams. In terms of capstone course teaching, not only do the teacher's guide every design development like Dutson et al. (1997) and Lee et al. (2019) suggested, clients and industry experts are invited to assess students' work, allowing the outcome to meet industry needs and conform to market standard. This approach validates Heitmann's (1996) theory that inviting external assessors to students' performance proved essential. At the end of every semester, the teachers summarise the students' overall performance, feedback from both the students and the clients, and result from teaching evaluation, and make modifications to next semester's course, assuring the curriculum meets everyone's needs. If any student experienced learning difficulties, the teachers would look into the problems and adjust the course's scope in the Plan stage. This reflection of the course requires extensive communication and modifications, but its spiral process enables the course to show improvement and differences each semester.

\section{Result}

By combining PBL, capstone course, and USR to the packaging design course at the Department of Cultural and Creative Industries of Hungkuang University, the study has accumulated three years of the teachers' teaching experience and course feedback and feedback from the project commissioners. This study discovers that such an integrated teaching method is helpful to students' learning and performance and can increase their knowledge of social responsibility. Based on the authors' teaching experience and the outcomes from the courses, this study proposes a new teaching strategy (Fig. 5) for the packaging design course. The course implementation can be carried out in a seven-stage process as follows:

1. Identifying the task: exploring current issues and determining the design proposition and scope after surveying and classifying the data. This train's student's ability to discover problems from the context and organising information collected. 
2. Defining the design field: conducting in-depth interviews, case studies, or workshops to define the scope of the design field after the case is introduced. Using any method or approach learned to identify its cultural features for further development.

3. Internalising information: internalising the information obtained from Steps 1 and 2 and summarising the contexts, textures, and design ideas. Different from other commercial designs, this process focuses on the cultural connection and localisation of the design.

4. Assigning roles and jobs: dividing work according to expertise and gradually exchanging information to build the design structure. Packaging design is interdisciplinary, so each member in the team providing his or her expertise is rather crucial to the success of the design proposition.

5. Conducting a self-review: repeatedly exchanging ideas among members of the group and participating in brainstorming sessions with the teachers. The different guidance provided enable students to think from different perspectives and judge the feasibility of their works more critically.

6. Reflecting on and deepening output: repeatedly thinking about design closure until finding the most suitable solution for output.

7. Displaying the design results: displaying the design results, collecting expert feedback, and making modifications to the final project. This allows students to know if their work is industry standard and what needs to be learned and modified.

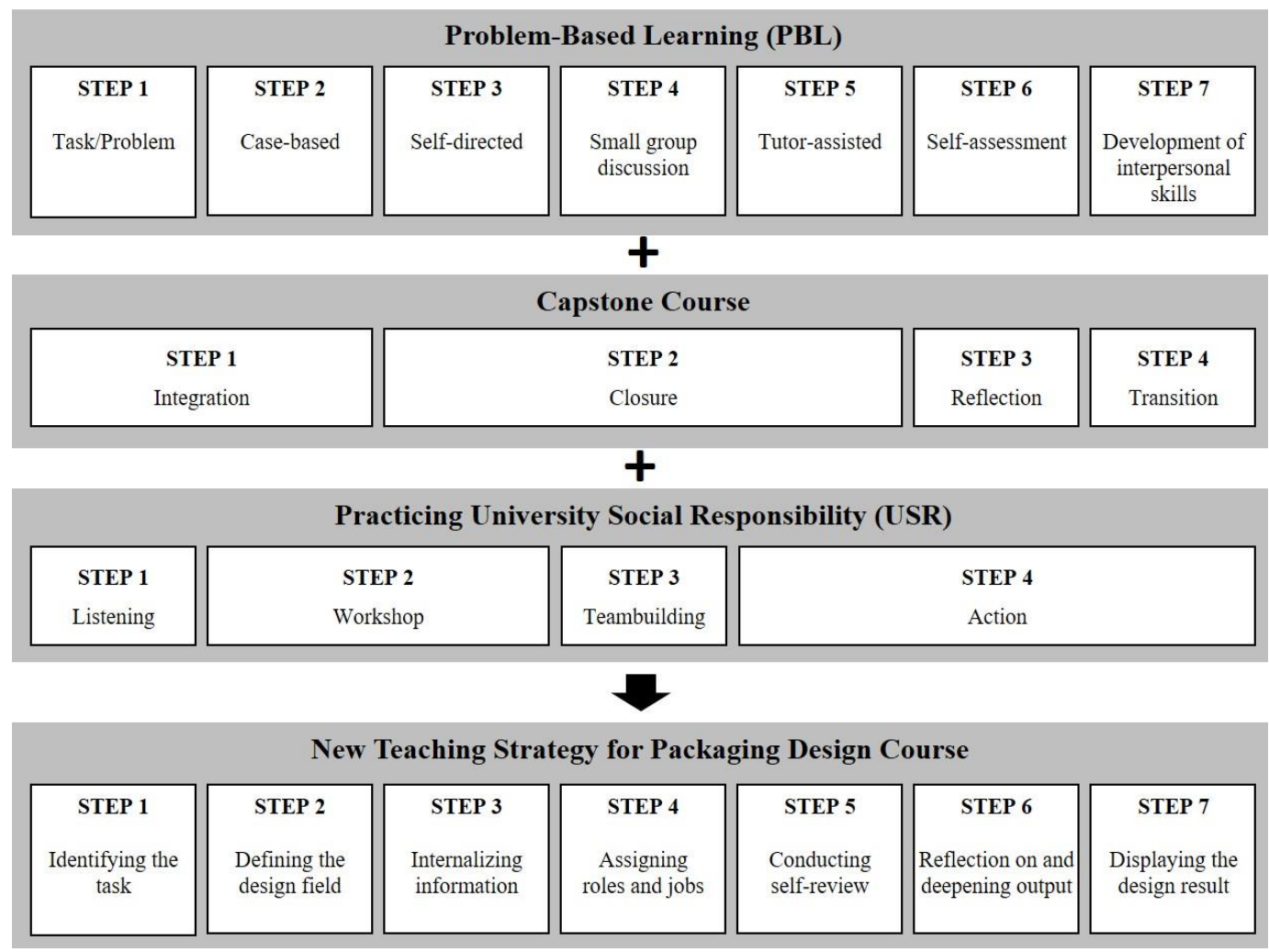

Figure 5. New Teaching Strategy for Packaging Design Course 
After three consecutive years of dynamic adjustments to the teaching strategies, this study has witnessed the transformation of students' learning, from their initial attempts to imitate the flashy design of existing products to have the ability to analyse product position, market demand, and user assessment professionally. Through case/field studies and assimilation of professional knowledge, students develop design ideas and produce suitable proposals as a team. To achieve the best result, students go through repeated discussions and modifications during the design process. The teacher only offers counselling and guidance and identifies problems to be resolved or corrected without giving subjective answers, thus allowing them to search for solutions and verify themselves. The final output is presented in a professional manner equivalent to that of industry practice. An opportunity is presented for students to interact with guest critics such as industry experts, representatives from the community, and clients. The proposal is finalised after feedback is collected and modifications are made.

This teaching strategy guides students to progress in stages. Students complained about the workload being too heavy initially, but gradually they were willing to devote more time and effort to group discussions and design. This is what the course was designed to achieve. Feedback from the school's teaching evaluations (Table 5) also shows positive growth in student learning and satisfaction.

Table 5. 2017-2020 Packaging Design I \&II Teaching Evaluation Scores

\begin{tabular}{ccc}
\hline Academic Year & $\begin{array}{c}\text { Packaging Design I } \\
\text { Maximum score of 5 }\end{array}$ & $\begin{array}{c}\text { Packaging Design II } \\
\text { Maximum score of 5 }\end{array}$ \\
\hline $2017-2018$ & 4.22 & 4.24 \\
\hline $2018-2019$ & 4.53 & 4.39 \\
\hline $2019-2020$ & 4.54 & 4.62 \\
\hline
\end{tabular}

Source: Teaching evaluations, Office of Academic Affairs, Hungkuang University

\section{Conclusion}

The packaging design course at the Department of Cultural and Creative Industries of Hungkuang University has been based on PBL since 2017. Subsequently, the course has combined the capstone course approach and the praxis of USR to build an integrated teaching framework for educating a new generation of design talents. The innovative strategy of the course is constructed through a seven-stage implementation process that addresses the shortcomings of traditional design education. It can also be applied to other professional design courses with adjustment according to the needs of different fields.

The study has made several contributions to the teaching of design courses. In terms of teaching strategy, the study provides design education with another innovative and effective method. This framework enables students to think in progressive stages to produce integrated and quality ideas. With regard to design topics, using real cases as assignments can motivate and inspire students. Many of the design works proposed by the students, such as the shampoo set packaging design and the Cancer-nono Foundation gift set packaging design, have been commercialised and are currently circulating in the market. Some even help the clients generate higher sales. These achievements set the foundation for future 
students who are thinking of pursuing their careers in design. From the perspective of improving students' competencies in design, the course also provides students with theoretical materials to enhance their professional knowledge. With the combination of their technical skills training, students can complete a design project, from the inception of assignment, market and cases analysis, development of ideas, to the final presentation, in a professional manner and standard as a team. This is evidenced by a group of students who won the Best Popularity Award for the Taichung Ah Yue Iced Black Tea Cup Design Competition in 2018 and three other students who won the top three Blue Sky Hotel Guest Room Design Competition prizes 2019.

Packaging design is a rapidly changing field, with new materials and structural designs constantly emerging. The teaching strategies need to be modified constantly in response to these changes to enhance learning efficacy. The course will allow students to connect with industry practices and bridge the gap between learning and application to better prepare them for future life.

\section{Suggestion and Limitation}

The hybrid teaching method hypothesised by the study is validated through third-year college students at Hungkuang University. They acquire active learning and critical thinking abilities, problem-solving skills when facing complex and interdisciplinary real-world problems, and understand the importance of social responsibility to the community. Hence, the study has the following suggestions for future research:

1. Besides the packaging design course, this hybrid teaching method can be applied to other design courses to fill any possible implementation process gap.

2. The integration of PBL, capstone course, and praxis of USR is a validated teaching method, but the teacher needs to spend twice as much time on preparation and teaching. The cost to carry out such a strategy can be a financial burden to the department and school.

3. Problem-based learning emphasises using group discussion to develop solutions. However, in practice, team members often determine the success of a discussion. In other words, groups with academically well-performed members are more likely to generate better outcomes than those without. Hence, if a group discussion did not go well, the teacher needs to be involved and assist in ensuring the

4. Due to time limitations, the study only spent three years collecting data from 16 respondents. Future research can increase the sampling number and research time for a more accurate result.

5. Future research can conduct control group experiments to compare the result based on hybrid teaching methods and traditional teaching methods.

\section{References}

Al-Busaidi, S., Yusuf, T., \& Reinders, H. (2021). A model for implementing problem-based language learning: Experiences from a seven-year journey. International Journal of Learning, Teaching and Educational Research, 20(1), 1-21. https://doi.org/10.26803/ijlter.20.1.1

Bender, N. W. (2012). Project-Based Learning: Differentiating Instruction for the 21st Century. Thousand Oaks, CA: Corwin Press. https://doi.org/10.4135/9781483387925.n2 
Bok, D. (1984). Beyond the ivory tower: Social responsibilities of the modern university. MA: Harvard University Press. https://doi.org/10.2307/40249026

Boyer, E. L. (1998). The Boyer Commission on Educating Undergraduates in the Research University, Reinventing Undergraduate Education: A Blueprint for America's Research Universities. Stony Brook, NY.

Chiang, Y. J., \& Chuang, H. Y. (2018). Integrating Collaboration of University and Indigenous Tribe for the Development of Tribal Tourism: A Case Study of Jialan Tribe in Jinfeng Township, Taitung. Sustainable Community-based Tourism Studies, 2(2), 1-18. https://doi.org/10.6744/SCTS.201812_2(2).0001

Duch, B. J., Groh, S. E., \& Allen, D. E. (2001). The power of problem-based learning: A practical 'how to' for teaching undergraduate courses in any discipline. Sterling, VA: Stylus.

Dutson, A. J., Todd, R. H., Magleby, S. P., \& Sorensen, C.D. (1997). A review of literature on teaching engineering design through project - oriented Capstone courses. Journal of Engineering Education, 86(1), 17-28. https://doi.org/ 10.1002/j.21689830.1997.tb00260.x

Fan, T. Y. (2019). Research on the Capstone course with PBL teaching method - taking the "Entrepreneurship" credits program as an example. Journal of Business Administration, 44(3), 75-96. https:// doi.org/10.3966/102596272019090443004

Gardner, J. N., \& Van der Veer, G. (1998). The senior year experience: Facilitating integration, reflection, closure, and transition. San Francisco, CA: Jossey-Bass.

Flipped Education and Action Learning Association (2018). Problem-based learning, PBL. http:/ /www.feala.org.tw/?p=5133

Hawks, J. S. (2014). The flipped classroom: Now or never? AANA Journal, 82(4), 264-269. https:// pubmed.ncbi.nlm.nih.gov/25167605/

Huang, K. H., \& Tsai, C. T. (2003). Practising the concept of course studies and development. Chung Cheng Educational Studies, 1(1), 1-20. https:// doi.org/10.6357/CCES.200304.0001

Heitmann, G. (1996). Project-oriented study and project-organised curricula: A brief review of intentions and solutions. European Journal of Engineering Education, 21(2), 121-131. https:// doi.org/10.1080/03043799608923395

Lee, L. S., Kung, H. Y., Chen, C. Y., \& Lin, K. Y. (2019). The influence of teaching strategies on learning effectiveness in the project-, problem- and inquiry-based Capstone course. Curriculum \& Instruction Quarterly, 22(3), 55-76. https://doi.org/10.6384/CIQ.201907_22(3).0003

Lewin, K. (1946). Action research and minority problems. Journal of Social Issues, 2(4), 3446. https://doi.org/10.1111/j.1540-4560.1946.tb02295.x

Matten, D., \& Moon, J. (2004). Corporate social responsibility education in Europe. Journal of Business Ethic, 54(4), 323-337. https:/ / doi.org/10.1007/s10551-004-1822-0

Ministry of Education. (2019). Technical and Professional Education Development Report: For the School Years of 2015 \& 2016. Taipei, Taiwan: Ministry of Education. https://tvet.ie.ntnu.edu.tw/sites/default/files/2019-

03/108\%E5\%B9\%B4\%E6\%8A \%80\%E8\%A1\%93\%E5\%8F\%8A\%E8\%81\%B7\%E6\% A5\%AD\%E6\%95\%99\%E8\%82\%B2\%E7\%99\%BC\%E5\%B1\%95\%E5\%A0\%B1\%E5\% 91\%8A \%E6\%9B\%B8\%28\%E7\%99\%BC\%E5\%B8\%83\%E7\%89\%88\%29.pdf

Oscarson, M. (1989). Self-assessment of language proficiency: Rationale and applications. Language Testing, 6(1), 1-13. https://doi.org/10.1177/026553228900600103

Tsai, C. T. (2007). The praxis of curriculum action studies. Curriculum \& Instruction Quarterly, 10(3), 75-89. https://doi.org/10.6384/CIQ.200707.0075

Tu, H., Lei, H. S., \& Huang, C. H. (2016). Problem-based learning: the effect of learning motivation on learning satisfaction. Commerce \& Management Quarterly, 17(4), 467491. https://doi.org/10.30083/CMQ 
Wu, C. F., \& Cheng, P. J. (2014). Capstone Course in the Realm of Design. Evaluation Bimonthly, 49, 32-34. https://doi.org/10.6445/EB

Wu, C. S. (2018). Educational terminology - USR. Pulse of Education by National Academy for Educational Research, 15, 1-2.

Wu, M. C. (2018). Practice of USR. Public Governance Quarterly, 6(1), 62-67.

Yamazaki, R. (2015). Community Design. Taipei, Taiwan: Faces Publishing.

Yamazaki, R. (2018). The Age of Community Design. Taipei, Taiwan: Faces Publishing.

Yang, K. Y., \& Chang, M. L. (2005). The theoretical background and teaching process of problem-based learning. Chung Yuan Journal, 33(2), 215-235. https://doi.org/10.6358/JCYU.200506.0215 